\title{
UNIFICATION OF SMART GRID AND RENEWABLE DISTRIBUTED GENERATION: A REVIEW
}

\author{
VIVEK SAXENA ${ }^{1}$, NARENDRA KUMAR ${ }^{2}$, UMA NANGIA ${ }^{3}$ \& MANISH KUMAR SINGH ${ }^{4}$ \\ ${ }^{1,4}$ A.B.E.S. Engineering College Ghaziabad, Uttar Pradesh, India \\ 1,2,3 Delhi Technological University, Delhi, India
}

\begin{abstract}
In the modern power system, smart grid structures is getting admiration and edify a path of complete greener way of energy generation. This paper highlights the each aspects of this framework to justify the energy demand in a she ltered, economical, trustworthy and environmental manner even the absence of storage structure at large level. It also facilitates the simultaneous objectives of demand monitoring and control with the amalgamation of renewable distributed generation having smart devices and storage system. A comprehensive review has been demonstrated with the smart operations unlike traditional power grid even the presence of some limitations for the establishment of advanced grid based power network. The analysis presented in this paper is driven by the eventuality of relic fuel calamity, ecological contamination, diminution of electrical energy, enlargement necessity of power system, newness to emergent trends in proficient energy utilization and regularly increasing electricity bill. Objective of this presentation is to review and examine the different aspects of smart grid framework for the progression of generation companies and consumer with reference to its development and advancement report, techno-economical contests, conceivable benefits and future scope.

KEYWORDS: Battery Storage, Demand Curve, Dispersed Generation, Energy Management, Renewable Sources, Smart Devices, Smart Grid
\end{abstract}

Received: Jun 06, 2020; Accepted: Jun 26, 2020; Published: Aug 31, 2020; Paper Id.: IJMPERDJUN2020973

\section{INTRODUCTION}

The increasing demand of green energy generation and end user anticipations has headed to the foreseeable statistic of developing a smart structure that can integrate the renewable energy source (RES) based generation with the overloaded centralized generation at an upper level. The complexities of traditional electrical power system are increasing day by day to meet the consumer expectations in view of electricity bill, demand satisfaction, pollutant reduction and intermittency of load (Santacana, 2010).

Moreover the increased cost, less reliability, passivity of equipment, absence of backup and reservations of conventional grid can be evaded with the smart operational grid technology i.e. smart grid having the smart operations; demand management, demand curve, dispersed generations, natural energy resource utilization, energy storage and smart devices. Real time monitoring and load control facility to consumer is the key exposure in such technology. Hence load scheduling competence and control the energy consumption from utility side makes it more valuable to sustain equilibrium between demand and supply. Renewable energy based generation is difficult to amalgamate with the traditional grid to implement demand subsequent technology (Ipakchi, 2009). Due to less reliability of RES, it is not feasible to facilitate the continuous generation that is necessary for the reliable operation amid distributors and consumers. Furthermore, significance of energy storage and demand response curve is also highlighted to overcome the effect of unpredictable nature of solar and wind power generation (Choi, 2011). 
The analysis presented in this paper is driven by the eventuality of relic fuel calamity, ecological contamination, diminution of electrical energy, enlargement necessity of power system, newness to emergent trends in proficient energy utilization and regularly increasing electricity bill. Objective of this presentation is to review and examine the different aspects of smart grid framework for the progression of generation companies and consumer with reference to its development and advancement report, techno-economical contests, conceivable benefits and future scope.

\section{SMART GRID}

Smart grid is a progression model of conventional power system that empowers the mutual benefits of each stakeholders with better utilization of green energy resources and smart metering devices. Additionally, it delivers the information based realistic approach to confirm the stable, reliable, economical, environmental and smart with the steps of monitoring, evaluating, verdict creation, regulatory and load shedding. On the basis of observations, assessment and optimization process, smart grid system has shown the potential with the help of smart metering system, load management server, advanced controllers and bidirectional information exchange amid utility and end users (Peng, 2011).Real time communication is necessary to enhance the effectiveness of this technology so that load requirement could be managed locally. In (Hou, 2011), authors presented the four basic features of smart grid; data, digitalization, robotics and communication. Moreover controlled methods are also particularized having a framework based on; power electronics, multi-agent system, smart fault management and simulated power plant. A comparative analysis is also substantial for this technology pertaining to the traditional one on the basis of uncertainties of RES and self-restoration properties. The risk analysis of RES utilization, necessity of prior planning of battery storage and user contribution are also established. A three step approach for the effective amalgamation of green energy sources suggested in which first step is characterized as building trust to engender an initial vision of communal to intercede for getting the socio-territorial classification and credentials of investors followed by second step of co-construction to deliberate among various ideas of stakeholders and prepare a mutual vision and concluded with the third step of ensuring sustainability having risk assessment based monitoring system (Palavicino, 2011). Investment and regulation policies are also important to enhance the impact of this technology because investors are fronting the demand of reinvestment to justify the new ecofriendly objectives. For such challenges, a hypothesis model has been investigated in centralized and decentralized mode to integrate the external parameters and find a crucial point of operation (Agrell, 2013). A detailed literature has been examined for the breach of various researcher's ideas about smart grid framework planning and execution (Moretti, 2017). Authors also presented a relative prejudiced investigation having many proficiency used for price and contaminant decrease, reason of encounter certification and investigation gap. Zigbee, Wireless Mesh, Power line communication, Cellular network communication and Digital subscriber lines are the developed communication technologies entertained for effective operation of grid and these technologies having their own frequency spectrum from $\mathrm{MHz}$ to $\mathrm{GHz}$ (1 $\mathrm{MHz}$ to $5.8 \mathrm{GHz}$ ), applications (advance metering system, demand response and home area network), advantages and shortcomings having same communication necessities like reservation, constancy, scalability and class of facility (Gungoor, 2011). To get the standard characteristics of smart grid, five area of concern has been prescribed and highlighted as; unified communication, sensing and dimension, unconventional components, advanced governor methods and enhanced interface with verdict provision (Gao, 2012). This technology plays a key role for convincing the use Renewable energy generation to meet the environmental challenges. The depletion of conventional grid idea and smart grid establishment ensures better efficiency, uninterrupted power supply, secured and reliable power structure. This enthusiastic methodology produces the prospects for the 21 st century electrical power system. Moreover, smart grid exhibits the properties like fast, secured, distributed, specific and intellectual in 
contrast of SCADA and other protection system (Amin, 2006). Transmission capabilities, competition in energy market, equipment utilization and synchronization between centralized and distributed resources are the main concerns for the existing grid system. For this criticality of operation, a remedial action plan has been prescribed by the authors with the framing of structure in the step of data collection, data acquisition system, communication, optimization with control, energy storage and smart metering devices (Lin, 2013). Framework of smart grid with different contributed units from generation to utilization is shown in figure1.

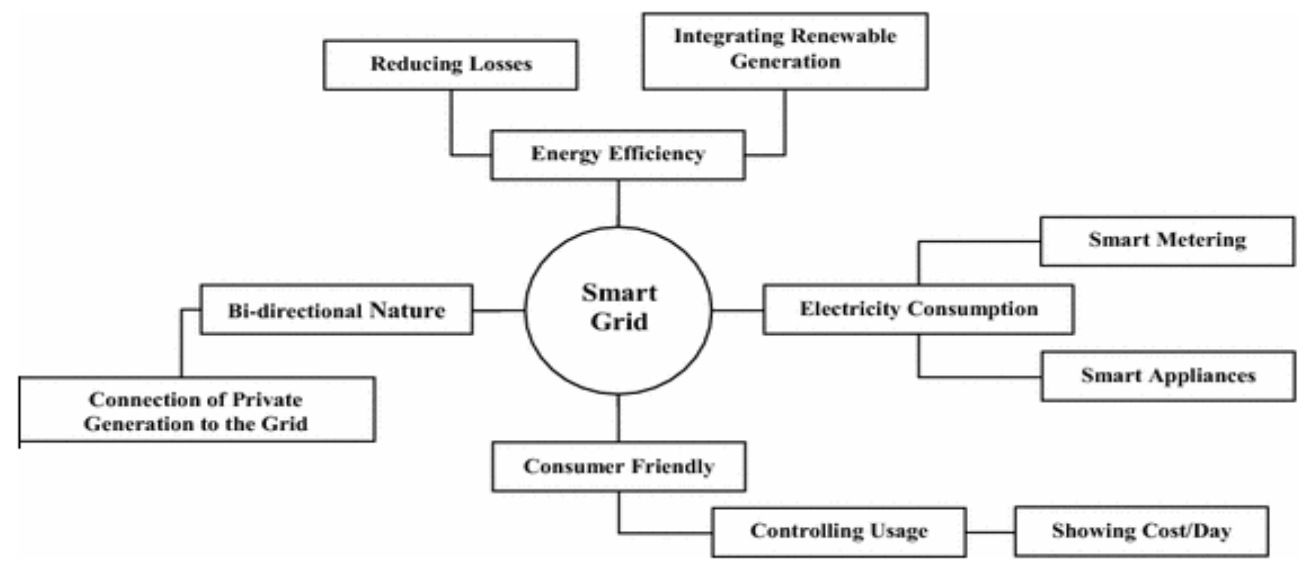

Figure 1: Smart Grid Framework.

\section{ENERGY DEMAND MANAGEMENT}

In conventional grid system, distribution companies are required to expand the power system to meet the day by day increasing demand. Extra cost for framing this agreement can be avoided with the efficient energy consumption and hence energy demand management (EDM) is implemented by the utilities under smart grid operation. Integrated resource planning method was created in the 1980s on the basis of proficient energy consumption in view of user friendly electricity bill and after that a new term is introduced i.e. EDM to normalize the power consumption by; reducing the regular demand, load shedding form loaded to unloaded hours and energy exchange (Masters, 2004). Furthermore, EDM based approaches could be classified as; cognizance programs, repayments on purchasing the equipment, inducements for manufacturer's well-wishers, price on the basis of utilization and advance metering system. Minimum error based optimization for EDM has been presented by using Monte Carlo simulation and highlighted the effect of several constraints and risk parameters with the addition of heat expedition (Ramanathan, 2008). Load framing techniques are shown in figure 2. Reduced energy utilization of user could be programmed by the utility side but there is an apprehension of user's confidentiality.

Numerous advantages can be retrieved with the use of EDM at different levels which includes society, producers and users. These benefits comprises reduction of; power plant expansion, electricity pricing, pollutant level, carrier opportunities, monthly bill, unsecured energy transmission, deficiency level, peak hours consumption, fossil fuel dependency and ignorance to emerging trends. To meet these challenges and extract the maximum benefits of EDM, technological strategies are explained in Table 1. 
Table 1: Technological Strategies for Maximizing the Benefits of EDM

\begin{tabular}{|l|l|}
\hline \multicolumn{1}{|c|}{ Technological Strategy } & \multicolumn{1}{c|}{ Explanation } \\
\hline Political inclination & $\begin{array}{l}\text { Political approval and administrative inclination towards this innovative approach } \\
\text { is the starting step. This favor will increase the faith of different stakeholders } \\
\text { (utility and user) to get the pre-planned objectives. }\end{array}$ \\
\hline Policy program & $\begin{array}{l}\text { Preparing a policy regarding regulations are necessary for the effective execution } \\
\text { within decided time duration. It will work as a solid base of this futuristic } \\
\text { approach to get the right direction. }\end{array}$ \\
\hline Mission and vision & $\begin{array}{l}\text { Initial stage planning is required for the efficacious DSM program } \\
\text { accomplishment. To get this long term goal it is strongly recommended to sketch } \\
\text { the blue prints and prepare a mission and vision after much thoughts on the basis } \\
\text { of analytical feedback reports and previous experiences. }\end{array}$ \\
\hline Finance for EDM programs & $\begin{array}{l}\text { Fund collection is another important aspect of any project. The level of fund } \\
\text { ensures the consistent and secured operations at low level, medium level and } \\
\text { large level stakeholders. Finance play a key role in different segments like } \\
\text { startup, setup and back up requirements of this EDM operations. }\end{array}$ \\
\hline Personal contribution & $\begin{array}{l}\text { Privatization of complete energy handling is not so far. Hence utility must also be } \\
\text { benefitted as per mutual agreement so that more contribution is expected at each } \\
\text { level of technological implementation to make this technology more successful. }\end{array}$ \\
\hline $\begin{array}{l}\text { Educational Program and } \\
\text { Development }\end{array}$ & $\begin{array}{l}\text { Educated and skilled workers are the back bone to nourish this technology and set } \\
\text { the new standards. The employees must be morally, technical and professionally } \\
\text { strong in their expertise area. }\end{array}$ \\
\hline
\end{tabular}

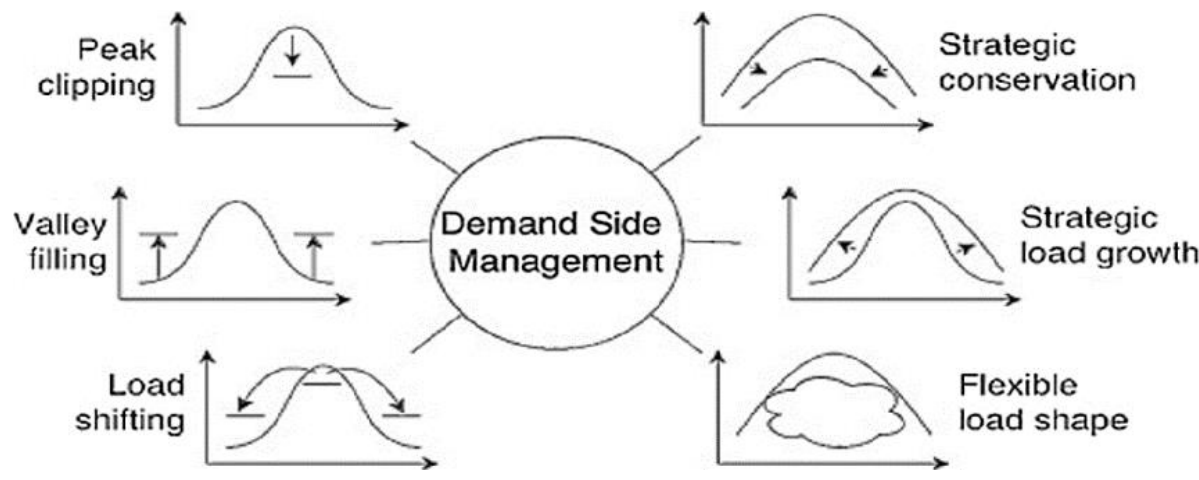

Figure 2: Loadframing Techniques.

\section{DEMAND RESPONSE}

Demand response refers to graphical presentation of energy demand and used to meet the supply challenges which are arose due to high level energy requirement and energy crisis. Previously, this term defines the reduction of maximum load hours annually but now the demand response or demand curve is also refer to reducing the energy consumption from buyer side with the intention of electricity cost per month and enticements on the basis of energy utilization [15]. Moreover, demand response curve can be classified on the basis of utility controlled and user controlled. Utility controlled comprises the direct load control of user from utility side in as per the prior agreement of both while in user controlled the demand is optimizing by the consumers as per the given tariff plan. There is no provision of incentive plans in conventional grid system because of this persons are not aware about the incentives for sifting their load hours in smart grid system (Krischen, 2004). Demand response programs is suggestively characterized on the evaluation of cost and merits. Consumers can be categorized on the basis of their utilization level. This subdivision has been carried out as; industrial consumers, marketing consumers and residing consumers and such type of users can participate in demand response methodology via reducing the energy consumption, swapping the load from peak hours to bottom hours and using distributed energy generation (Jamshid, 2013). An example of direct load control has been demonstrated by using electric 
geyser and such approach has shown the effectiveness for falling the load level by changing the operating hours and mean saving in ingestion of energy (family wise) in the end of the day have been concluded which reduced the payback period (Torgeir, 2009). Fine factor has been suggested in interruptible program and capacity market program of demand response for violating the mutually decided rules for energy consumption (Aalami, 2010). The demand buyback is also a part of demand response program wherein the load arrangement is reformed by industrial consumers to acquire the financial enticements. Supplier and customer, both are profited and diminish the market clearing cost using peak hours having the capacity and security limitations of plant (Saebi, 2010). Emergency demand response algorithm has been revealed for the promising disbursement of the scheme and validated the conditions like objective to burdened node, sufficient house selection and boomerang after emergency (Tyagi, 2010). Time and cost parameter consideration and optimization is also important in demand characteristic evaluation and these parameters may be included as an objective function with the load optimization process in smart grid.

\section{DISTRIBUTED GENERATION}

Distributed generation (DG) is a heart of smart grid based power structure and creates various innovative opportunities from energy generation to energy utilization with green energy production. DG is also known as decentralized or dispersed generation which are situated in the purlieu of consumers and unlike from the outdated central generation. DG is very much popular in energy sector due to its technical, fiscal and ecological benefits. These benefits could be extracted by optimal DG allocation, in which size and location of DG are optimized with the consideration of existing limitations (Khattam, 2004). DG allocation and planning has a number of objectives like; enhancement of supplied energy parameters, cost optimization and pollutant reduction but the barricades are also contemporaneous. These constraints have different sources and properties and subdivided as; technical barrier, financial barrier and socio-political barrier. Such constraints are considered during the optimization planning and process of DG framework having single objective or multi objective function. Numerous techniques of DG optimization have been implemented and have a broad classification as; basic search algorithms, nature inspired algorithms and hybrid intelligent algorithms. Structural planning of DG consisted a sequence of operations like configure the system design, assessment of RES, load calculation, system formulation, optimization method and elucidation of outcomes. DG system configuration is also labelled the capacity, numbers and types of generating units. Generating units may be single DG unit or multiple DG units and it may be renewable energy based or fossil fuel generation. It is essential to ensure the pre-assessment of RES owing to intermittency in energy generation and also required the planning with weather forecasting data and experimental data. In the optimistic world, the natural source utilization has been meticulously accepted at different level with the observation, appreciation and diffusion of RES to break the hierarchy of fossil fuel based centralized generation [23-25].

\section{Role of Renewable Energy Source}

In the modern era, RES utilization is must with the prospective of pollution free energy generation to encounter the increasing demand scenario in an atmospheric pleasant manner without perturbing the fossil fuel availability. Integration of RES has great significance for maximizing the benefits from smart grid operation and directing to economical and effluence free energy generation even several measures have been applied for the inspection of ecological impact in previous years. In (Gao, 2014), replacement of coal power plant with the renewable energy generation has been recommended in an approach of cost saving. Renewable DG optimization could extract maximum benefits in terms of environment factor and cost factor. In view of above benefits, DG model has been successfully compared by considering 
the relative exploration of impurity discharge from adequate fuel based generation and RES based generation (Sui, 2010). A penalty could be imposed for violating the policy rules and standards related to the atmospheric pollution and health hazards. It is very much essential to develop the faith on natural sources of generation at various level of users because weather forecasting data, periodic data, experimental data, observational data are not so much precise and a pre-assessment is required for introducing the RES generation (Izadyar, 2016). Subsequently, energy generation based on the agriculture is obligatory to ascertain the continuous feed stock of primary material for the reliable and uninterrupted energy generation. Tidal energy generation is more consistent in contrast of solar and wind energy generation even it has varying characteristic (Kim, 2016). Consequently, dualistic approaches have been characterized for solar and wind power resource convenience; experimental atmospheric data dimension and climatological data prediction (Zhou, 2010).

\section{Battery Storage}

Energy storage is essential for completing the objectives of smart grid operations and high level unification of intermittent RES. A short-range energy storage method is integrated with doubly fed induction generator for levelling the power variations and steadying the dc bus operation of wind energy based plant and hence rise the capacity of low voltage trip (Abbey, 2007). Energy storage is categorized on the basis of storage mode of charge. In continuation of this classification, various medium of energy storage are electrical, mechanical, chemical and thermal (Mahlia, 2014). Authors also concluded that required challenges of atmospheric pollutions motivate the traditional energy infrastructure to adopt this smart generation methodology and it needs energy storage to materialize the fossil fuel from RES. Historic development of energy storage methods, restraints and applications have been ominously exposed. Authors in (Kousksou, 2014) presented a comprehensive analysis of energy storage technologies on the factors; technological development, power capacity, deliverance time, stowing time, principal amount, phase efficiency, energy concentration, life and environmental impact. The current development of various energy storage technologies has been reviewed for academic level as well as industrial level by taking the consideration of power quality parameters and cost (Luo, 205). In continuation, profited application segments of energy storage consumption are also acknowledged by the authors and these enhancements are; power eminence, journey over competences, energy management, demand smoothing, peak shearing, interval swapping, voltage regulation, spinning reserve, oscillation suppressor, spring energy storage and power tie-up for telecommunication. Assortment of suitable system for energy storage is also important for the energy storage of RES incorporation and it depends on the monetary feasibility, lifecycle duration, effectiveness, system capability, green impression and assimilated methodological aspects (Suberu, 2014). Authors also highlighted requirement of energy back-up for the driving factors of natural source generation having the modelling parameters like load handling, intermittent nature of RES, power quality parameter optimization, smart device development, power system expansion plan and progression of smart grid.

\section{SMART DEVICES}

Smart devices are the brain of smart grid structures and broadly classified as smart metering system and communication system. Modern grid system consisted the smart energy meter, digital display and advanced communication devices so that it safeguards the sustained segments. For stable and secured operation, utility and user are required to take the responsibility of bilateral information exchange. Information exchange could be set up via wire or wireless structure under the regulation of hardware and software security groups to circumvent any risk (Kabalci, 2016). Along with smart device utilization, advance protection systems in renewable DG unification with smart grid are required and could ensure the promising and enhanced energy generation [37-39]. 


\section{CONCLUSIONS}

This paper has elaborated the smart operations of this non-conventional grid structure to the incorporation of renewable energy based distributed sources having charge storage facility and controlled by smart devices to follow the policy of demand curve and management. A summary of key finding are given in Table 2.Moreover, this review also presents the evidence of witnessing for the testimonial of reconfigured, advanced, intelligent and environmental friendly energy structure though conventional grid system is dominating in many countries. Implementation of climatologically model, objective based policy, socio-political acceptance and skilled workers can elevate the extraction of maximum benefits and break the conventional hierarchy of load utilization and dependency on fossil fuel. User friendly regulations, incentive policies, enhanced power quality, uninterrupted supply, RES utilization, scope of energy storage, advance communication system and local energy generation facilities are the various fragments of this technological deployment. The present challenges of demand contentment, pollutant reduction, less electricity bill, cognizance to emerging techniques and efficient energy utilization has been entertained by using renewably unified DG planning in the smart grid organization.

\section{Table 2: Key Findings of Smart Grid Framework}

\begin{tabular}{|l|l|}
\hline Structural Process & \multicolumn{1}{c|}{ Key findings } \\
\hline Smart Grid & $\begin{array}{l}\text { Smart Grid has a potential to cultivate a modern power system with a revolutionary } \\
\text { approach of self-healing system framework to meet the new challenges of increasing } \\
\text { demands and healthy atmosphere. }\end{array}$ \\
\hline EDM & $\begin{array}{l}\text { EDM is a tool for maximizing the reciprocated benefits of utility and consumer side. } \\
\text { An appropriate assessment and policy framework can create a landmark on the way. }\end{array}$ \\
\hline Demand response & $\begin{array}{l}\text { Demand response has the ability to enhance the quality of power generation, } \\
\text { transmission and distribution by shifting the load under the certain challenges like } \\
\text { market role, extra expenditure, tariff plan and technological development. }\end{array}$ \\
\hline DG & $\begin{array}{l}\text { Enhanced objective based DG planning and optimization process depends on the } \\
\text { optimization process, objective function, driving factors, optimized results and } \\
\text { improved outcomes subjected to the technical or financial or ecological constraints. }\end{array}$ \\
\hline RES & $\begin{array}{l}\text { The barrier of natural source utilization is the intermittent nature and ecological } \\
\text { conditions. For the effective integration of RES it is recommended to develop a } \\
\text { consistent assessment model of climatological data forecasting and planning. }\end{array}$ \\
\hline Battery storage & $\begin{array}{l}\text { Energy storage is dependent on the temperature change, electrode degradation and fuel } \\
\text { cell deficit, hence a comprehensive hydrogen stowage is desirable. }\end{array}$ \\
\hline Smart devices & $\begin{array}{l}\text { Smart devices handling are very sensitive with the purpose of delivering consistent and } \\
\text { secured energy supply without compromising the privacy of customers. }\end{array}$ \\
\hline
\end{tabular}

\section{REFERENCES}

1. Santacana, Rackliffe, Tang, Feng. (2010). Getting Smart.InIEEE Power Energy Mag, vol. 8, no. 2, (pp. 41-48).

2. Ipakchi,Albuyeh. (2009). Grid of the future.In IEEE Power Energy Mag, vol. 7, no. 2, (pp.52-62).

3. Choi, Lee, Hong. (2011). Implementation and evaluation of the apparatus for intelligent energy management to apply to the smart grid at home. In: Proceedings of the 2011 IEEE International Instrumentation and Measurement Technology Conference, Binjiang, (pp. 1-5).

4. Pawar, A. N. J. A. L. I., and S. A. N. D. I. P. Rahane. "Opportunities and challenges of wireless communication technologies for Smart Grid applications." International Journal of Computer Networking, Wireless and Mobile Communications (IJCNWMC) 3.1 (2013): 289-296.

5. Peng, Yan. (2011). Clean energy grid-connected technology based on smart grid. In Energy Procedia, (pp. 213-218). 
6. Hou, Zhou,Zhang,He. (2011).A brief analysis on differences of risk assessment between smart grid and traditional power grid. In: Proceedings of the 2011 Fourth International Symposium on Knowledge Acquisition and Modeling, Sanya, (pp. 188-191).

7. Alvial-Palavicino, Garrido-Echeverria, Jimenez-Estevez, Reyes. (2011). A methodology for community engagement in the introduction of renewable based smart micro grid In Energy Sustain Dev, vol. 15, (pp. 314-23).

8. Patil, Bhagyashree, and MarutiLimkar. "Machine to Machine Communication Based Electricity Monitoring and Billing System." International Journal of Electrical and Electronics Engineering Research (IJEEER) ISSN (P) (2016).

9. Agrell,Bogetoft, Mikkers. (2013). Smart-grid investments, regulation and organization. In Energy Policy, vol. 52, (pp. 65666).

10. Moretti, NjakouDjomo, Azadi, May. (2017). A systematic review of environmental and economic impacts of smart grids. In Renew Sustain Energy Rev, vol. 68, (pp. 888-98).

11. Gungor. (2011). Smart grid technologies: communication technologies and standards. In IEEE Trans Ind Inform, vol. 7, no. 4, (pp. 529-39).

12. Sekhar, P. Chandra. "A Super Conductor Fault Current Limiter for Grid Connected Wind Energy System." International Journal of Electrical and Electronics Engineering Research (IJEEER) 3.3 (2013): 119-126.

13. Gao,Xiao, Liu, Liang. (2012). A survey of communication/networking in smart grids. In Future GenerComputSyst, vol. 11, (pp. 391-404.)

14. Amin, Wollenberg (2006). Toward a smart grid: power delivery for the 21st century. In IEEE Power Energy Mag, vol. 4, no. 6 , (pp. 34-41).

15. Lin, Chen. (2013). Distributed optimal power flow for smart grid transmission system with renewable energy sources. In Energy, vol. 56, no. 3, (pp. 184-92).

16. Masters. (2004).,Renewable and efficient electric power systems. InHoboken, NJ: Wiley.

17. Ramanathan, Vittal.(2008). A framework for evaluation of advanced direct load control with minimum disruption. In IEEE Trans Power Syst, vol. 23, no. 4, (pp. 1681-8).

18. Bepery, Chinmay, et al. "Advanced home automation system using Raspberry-Pi and Arduino." International Journal of Computer Science and Engineering 8.8 (2019): 1-10.

19. STAFF REPORT. (2010). National action plan on demand response," in FERC.

20. Kirschen, Strbac. (2004). Fundamentals of power system economics. In New York: John Wiley \& Sons.

21. Jamshid, Mohammad-Iman. (2013). Demand response in smart electricity grids equipped with renewable energy sources: a review. In Renew Sustain Energy Rev, vol. 18, (pp. 64-72).

22. Torgeir. (2009). Direct load control of residential water heaters. In Energy Policy, vol. 37, no. 9, (pp. 3502-12).

23. Aalami, Moghaddam, Yousefi. (2010).Demand response modeling considering Interruptible/curtailable loads and capacity market programs, " in Appl Energy, vol. 87, no. 1, (pp. 243-50).

24. Saebi, Taheri, Mohammadi, Nayer. (2010).Demand bidding/buyback modeling and its impact on market clearing price. In: Proceedings of the 2010 IEEE International Energy Conference, Manama, (pp. 791-796).

25. Tyagi, Black,(2010).Emergency demand response for distribution system contingencies. InIEEE PES T \& D 2010, New Orleans, LA, USA, (pp. 1-4). 
26. Khattam, Salama. (2004).Distributed generation technologies, definitions and benefits. InElectr Power Syst Res, vol. 71, (pp. $119-28)$

27. Villena, Fonteneau, Gautier, Ernst. (2019).Evaluating the evolution of distribution networks under different regulatory frameworks with multi-agent modelling. InEnergies, vol. 12, no. 7, (pp. 1203).

28. Wolsink. (2020).Distributed energy systems as common goods: Socio-political acceptance of renewables in intelligent microgrids. InRenew Sustain Energy Rev, vol. 127.

29. Laurentis. (2020).Mediating the form and direction of regional sustainable development: the role of the state in renewable energy deployment in selected regions. InEuropean Urban and Regional Studies.

30. Gao, Liu, Yang, Liang, Zhang. (2014).Multi-objective planning of multi-type distributed generation considering timing characteristics and environmental benefits. InEnergies, vol. 7, no. 10, 2014, (pp. 6242-57).

31. Sui. (2010).The distribution network reliability and economy study considering the distribution generation. InChengdu, China: Southwest Jiaotong University, 2010.

32. Izadyar, Ong, Chong, Leong. (2016).Resource assessment of the renewable energy potential for a remote area: a review. InRenew Sustain Energy Rev, vol. 62, 2016, (pp. 908-23).

33. Kim, Lee, Wata, Hyun, Lee. (2016).Experiments on the magnetic coupling in a small scale counter rotating marine current turbine. InMater SciEng, (pp. 129).

34. Zhou, Lou, Li, Hu, Yang. . (2010).Current status of research on optimum sizing of stand-alone hybrid solar-wind power generation systems. In Appl Energy, vol. 87, (pp. 380-9).

35. Abbey, Joos. (2007).Super capacitor energy storage for wind energy application. InIEEE Trans IndAppl, vol. 88, no.3, (pp. 769-76).

36. Mahlia, Saktisahdan, Jannifar, Hasan. (2014).A review of available methods and development on energy storage: technology update. In Renew Sustain Energy Rev, vol. 33, (pp. 532-45).

37. Kousksou, Bruel, Jamil, Rhafiki. (2014).Energy storage: applications and challenges. In Sol Energy Mater Sol Cells, vol. 120 , (pp. 59-80).

38. Luo, Wang, Dooner, Clarke. (2015). Overview of current development in electrical energy storage technologies and the application potential in power system operation. InAppl Energy, vol. 137, ( pp. 511-36).

39. Suberu, Wazir, Bashir. (2014).Energy storage systems for renewable energy power sector integration and mitigation of intermittency. InRenew Sustain Energy Rev, vol. 35, (pp. 499-514).

40. Kabalci. (2016).A survey on smart metering and smart grid communication. In Renew Sustain Energy Rev, vol. 57, (pp. 30218).

41. Lamsal, Sreeram, Mishra, Kumar. (2019).Output power smoothing control approaches for wind and photovoltaic generation systems: à review. In Renew Sustain Energy Rev, vol.113.

42. Tsimtsios, Korres, Nikolaidis. (2019).A pilot-based distance protection scheme for meshed distribution system with distributed generation. InInt J Electr Power EnegySyst, vol. 105, (pp. 454-69).

43. Barraa, Courya, Fernandesb. (2020).A Survey on adaptive protection of micro grids and distribution systems with distributed generators. In Renew Sustain EnergyRev, vol. 118. 

